\title{
Stan warstwy wierzchniej po laserowej oraz laserowo-mechanicznej modyfikacji powierzchni
}

\author{
Surface integrity after laser \\ and laser-mechanical surface modification
}

\section{Streszczenie}

W pracy przedstawiono analizę stanu warstwy wierzchniej po laserowym stopowaniu stali Stellitem 6 oraz obróbce hybrydowej łączącej laserowe stopowaniem z obróbką nagniataniem. Obróbka hybrydowa prowadzona była na stanowisku laserowym. Do realizacji procesu nagniatania powierzchni wykorzystano głowicę do nagniatania ślizgowego umożliwiającą obróbkę w podwyższonych temperaturach jak i na zimno. Ocenę efektów obróbki hybrydowej przeprowadzono na podstawie badań chropowatości, mikrostruktury, mikrotwardości oraz badań naprężeń własnych.

Słowa kluczowe: stopowanie laserowe; nagniatanie; obróbka hybrydowa

\section{Abstract}

The results of experiments on the application of the new hybrid method, which combines the laser alloying process with slide burnishing, were presented. Both treatments were performed on the laser stage in one operation. The experiments were done on carbon steel alloyed with Stellite 6 . The results of analysis of the surface roughness, microstructure, microhardness and residual stresses in surface layer after the laser alloying process and laser alloying combined with burnishing were presented.

Keywords: laser alloying; burnishing; hybrid treatment

\section{Wstęp}

Modyfikacja warstwy wierzchniej (WW) metali i stopów wiązką laserową wykorzystywana jest w szeregu obróbkach powierzchniowych: stopowaniu, natapianiu, hartowaniu przetopieniowym. W wyniku przetopienia uzyskuje się zwykle ujednorodnienie, rozdrobnienie ziarna oraz wzrost twardości WW. W przypadku stopowania, wtapiania i natapiania dodatkowo możliwa jest zmiana składu chemicznego utworzonej warstwy.

Obróbki związane z przetopieniem generalnie prowadzą do powstawania naprężeń rozciągających, co związane jest z procesami grzania i chłodzenia ulepszonej warstwy $[1,2]$. Wartość naprężenia zależy od parametrów obróbki laserowej tj. gęstość mocy promieniowania, sposób obróbki laserowej czy jest to pojedyncze przejście czy obróbka wielościeżkowa, stopnia przykrycia ścieżek a także rodzaj materiału i przemian fazowych zachodzących w trakcie obróbki. Wartość naprężenia zależy również od przyjętej metody

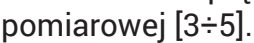

Naprężenia rozciągające $\mathrm{w}$ warstwie wierzchniej mają niekorzystny wpływ na niektóre własności eksploatacyjne a w szczególności wytrzymałość zmęczeniową. Próby redukcji naprężenia oraz zmniejszenia chropowatości po przetapianiu laserowym poprzez powierzchniową obróbkę plastyczną zostały przeprowadzone w pracy [6]. Warstwę wytworzoną poprzez stopowanie laserowe poddano rolowaniu w wyniku, czego uzyskano redukcję naprężenia rozciągających oraz zmniejszenie wysokości chropowatości. Innym rozwiązaniem jest zastosowanie klasycznego procesu "shot peening" po przetapianiu laserowym [7]. W wyniku hartowania przetopieniowego stali wiązką laserową i kulowania uzyskano zmianę naprężeń rozciągających w warstwie wierzchniej z + $1200 \mathrm{MPa}$ do - $900 \mathrm{MPa}$, w strefie o grubości około $70 \mu \mathrm{m}$. Zastosowana obróbka pomimo spadku twardości materiału spowodowała dwukrotny wzrost odporności na zużycie przez tarcie.

Analizując możliwość konstytuowania warstwy wierzchniej o wysokiej gładkości, można zauważyć, że proces mechanicznego kształtowania tekstury jest bardziej efektywny w wysokich temperaturach, gdy materiał jest plastyczny. Proces nagrzewania laserowego $z$ powodzeniem stosowany jest do wspomagania obróbki mechanicznej materiałów trudno obrabialnych np. do cięcia, toczenia twardej ceramiki [8], toczenia, frezowania oraz szlifowania takich materiałów jak stopy tytanu, żeliwo oraz stale specjalne [9].

W pracy przedstawiono wyniki badań stanu WW stali po stopowaniu laserowym Stellitem 6 oraz po zastosowaniu metody hybrydowej łączącej proces stopowania laserowego z procesem nagniatania powierzchniowego. Proces nagniatania był prowadzony bezpośrednio na stanowisku laserowym

Dr hab. inż. Joanna Radziejewska, prof. PW, - Instytut Technik Wytwarzania, Politechnika Warszawska. 
w jednej operacji z procesem stopowania. Nagniatanie realizowano w dwuetapowo - wygładzanie powierzchni uzyskano poprzez plastyczne odkształcenia warstwy wierzchniej w wysokiej temperaturze, a redukcję naprężeń rozciągających w warstwie wierzchniej osiągnięto poprzez obróbkę plastyczną w zakresie niskich wartości temperatury.

\section{Metodyka badań}

Stopowanie laserowe oraz obróbkę laserowo - mechaniczną warstwy wierzchniej przeprowadzono wykorzystując laser $\mathrm{CO}_{2}$ o mocy maksymalnej $2,5 \mathrm{~kW}$, generujący wiązkę osiowo-symetryczną o modzie bliskim TEM10, która była ogniskowana soczewką ZnSe o ogniskowej 5". Laserowe stopowanie i obróbkę hybrydową (laserowe stopowanie z jednoczesnym nagniataniem ślizgowym) przeprowadzono dlapróbekzestaliwęglowej,45naktóreuprzednionałożonoplazmowo warstwę stellitu kobaltowego o grubości około $300 \mu \mathrm{m}$ o składzie chemicznym: $45 \%$ Co, $30 \%$ Cr, 13\%W, 0,8\% C.

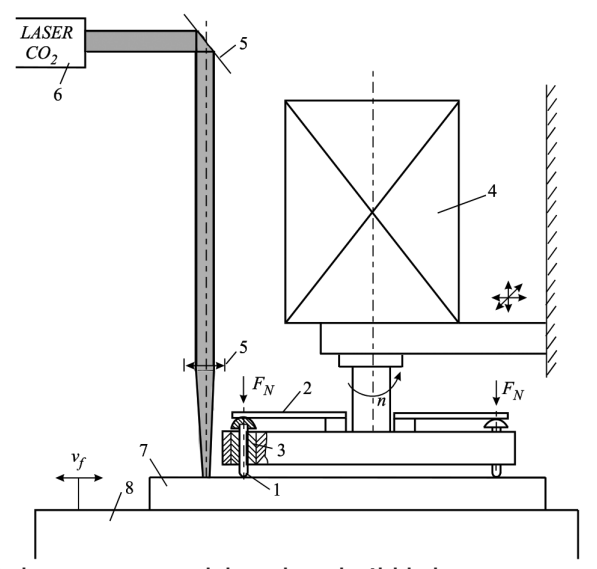

Rys. 1. Schemat stanowiska do obróbki laserowo-mechanicznej: 1 - element nagniatający, 2 - sprężyna, 3 - łożysko obrotowe, 4 - napęd, 5 - zwierciadło, 6 - laser $\mathrm{CO}_{2}, 7$ - próbka, 8 - stół roboczy, 9 - soczewka Fig. 1. Scheme of the laser-mechanical machining station: 1 - burnishing element, 2 - spring, 3 - rotational bearing, 4 - power feed, 5 - mirror, 6 - laser $\mathrm{CO}_{2}, 7$ - sample, 8 - working table, 9 - lens

Obróbkę nagniataniem prowadzono jednocześnie z laserowym przetapianiem wykorzystując specjalnie skonstruowaną głowicę do nagniatania ślizgowego. Jej konstrukcja umożliwia osiągnięcie korzystnej struktury geometrycznej powierzchni poprzez redukcję chropowatości i falistości (eliminując proces szlifowania po procesie obróbki laserowej związanej z przetopieniem) oraz zmniejszenie naprężeń rozciągających w warstwie wierzchniej występujących po przetopieniu [10].

Elementy nagniatające, wykonane z węglika spiekanego, rozmieszczono na różnych promieniach tak, by pierwszy (na większym promieniu) oddziaływał na warstwę pozostającą w wysokiej temperaturze i ją wygładzał, a drugi działając na warstwę o niższej temperaturze generował w niej naprężenia ściskające. Odległość elementu nagniatającego od osi wiązki laserowej wstępnie dobrano na podstawie obliczeń rozkładu temperatury na powierzchni materiału. Szczegółowy opis konstrukcji stanowiska przedstawiono w pracy [10].

W pierwszym etapie badań określono najkorzystniejsze warunki hybrydowej obróbki dla stopowania pojedynczej ścieżki, następnie przeprowadzono obróbkę większych powierzchni poprzez skanowanie wielościeżkowe z różnym stopniem przykrycia ścieżek (30 do 50\%).

Badania topografii powierzchni przeprowadzono na profilometrze skaninngowym. Wartości parametrów chropowatości wyznaczono dla pola o wymiarach $1.4 \mathrm{~mm} \times 4 \mathrm{~mm}$.
Pomiary prowadzono dla $\mathrm{dx}=0.5 \mu \mathrm{m}, \mathrm{dy}=5 \mu \mathrm{m}$ promień zaokrąglenia igły $2 \mu \mathrm{m}$. Pomiary profilowe zostały przeprowadzone dla odcinka pomiarowego równoległego do prędkości posuwu w środkowej części strefy przetopienia.

Ocenę zmian strukturalnych przeprowadzono na zgładach metalograficznych w przekroju prostopadłym do kierunku skanowania wiązką laserową. Mikrostrukturę materiału analizowano na mikroskopie optycznym oraz dla wybranych próbek na SEM i TEM. Na podstawie obserwacji mikroskopowych określono kształt strefy przetopionej, jej maksymalną głębokość i szerokość, rozmiary strefy wpływu ciepła. Na zgładach przeprowadzono pomiary mikrotwardości przy obciążeniu 20 G. Badania rozkładu naprężeń resztkowych przeprowadzono dla próbek po procesie stopowania laserowego oraz po obróbce hybrydowej metodą rentgenowską [10].

\section{Wyniki badań}

Badania wykazały, że najkorzystniejsze efekty obróbki dla procesu stopowania pojedynczych ścieżek uzyskano dla mocy lasera $-2 \mathrm{~kW}$, prędkość skanowania $\mathrm{v}_{\mathrm{f}}=0,1$ i 0,2 $\mathrm{m} / \mathrm{min}$, średnicy wiązki - 2 do $3 \mathrm{~mm}$. Proces stopowania większych powierzchni przeprowadzono poprzez wykonywanie wiązką lasera sześciu równoległych do siebie ścieżek przy stopniu przykrycia ścieżek na powierzchni około $50 \%$. Proces nagniatania prowadzono przy prędkości obrotowej głowicy $550 \mathrm{obr} / \mathrm{min}$ i sile nacisku 65 i $100 \mathrm{~N}$.

\section{Struktura geometryczna powierzchni}

Pomiary chropowatości powierzchni wykazały, że we wszystkich przypadkach zastosowania procesu nagniatania nastąpiło wygładzenie powierzchni w stosunku do próbek tylko stopowanych. Na rysunku 2 przedstawiono widok 3D powierzchni stopowanej oraz po obróbce hybrydowej.
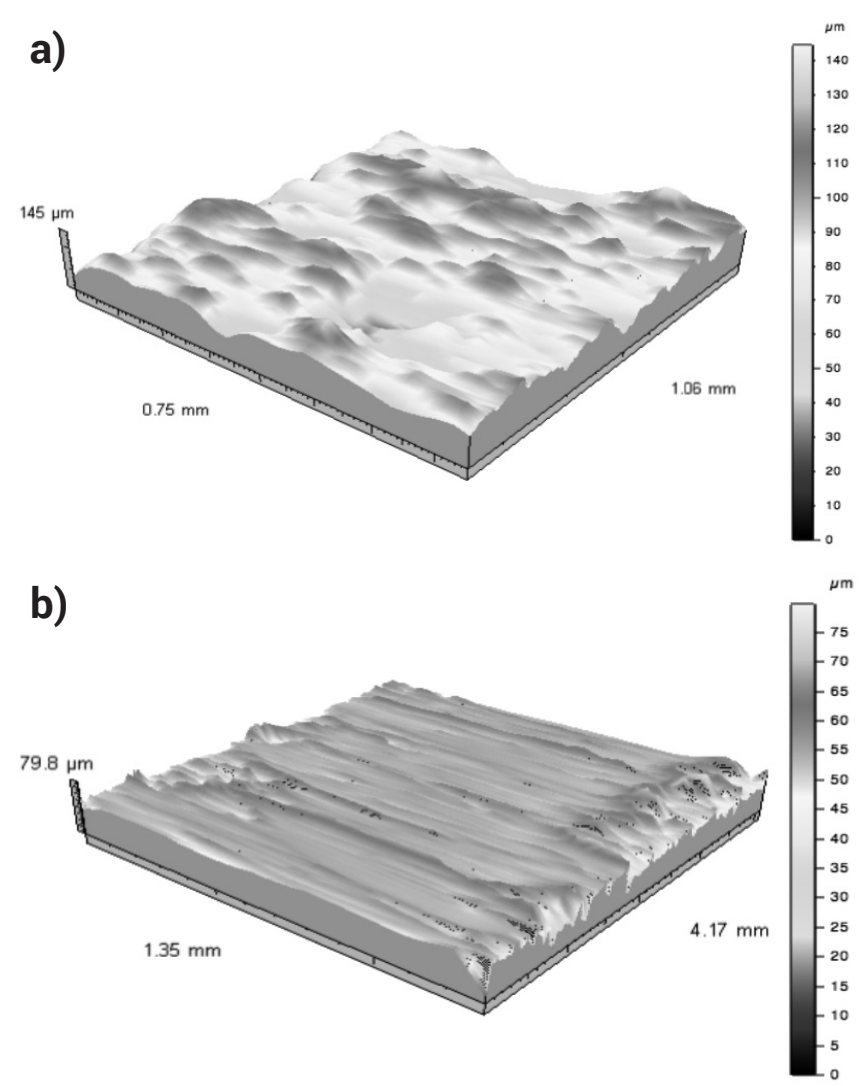

Rys. 2. Widok powierzchni po: a - stopowaniu laserowym, b - obróbce hybrydowej

Fig. 2. 3-D view surface after. a - laser alloying and b - hybrid treatment 
Tablica I. Parametry 2D i 3D chropowatości powierzchni po stopowaniu i obróbce hybrydowej Table I. 3D and 2D roughness parameters after laser alloying and hybrid treatment

\begin{tabular}{|c|c|c|c|c|c|c|c|c|}
\hline \multirow{3}{*}{$\begin{array}{c}\mathrm{V}_{\mathrm{f}} \\
{[\mathrm{mm} / \mathrm{min}]}\end{array}$} & $\begin{array}{c}\mathrm{X} \\
{[\mathrm{mm}]}\end{array}$ & $\begin{array}{c}\mathrm{Sa} \\
{[\mu \mathrm{m}]}\end{array}$ & $\begin{array}{c}\mathrm{Sp} \\
{[\mu \mathrm{m}]}\end{array}$ & $\begin{array}{c}\mathrm{Sy} \\
{[\mu \mathrm{m}]}\end{array}$ & $\begin{array}{c}\mathrm{Ra} \\
{[\mu \mathrm{m}]}\end{array}$ & $\begin{array}{c}\mathrm{Rz} \\
{[\mu \mathrm{m}]}\end{array}$ & $\begin{array}{c}\mathrm{Wa} \\
{[\mu \mathrm{m}]}\end{array}$ & $\begin{array}{c}\mathrm{Wt} \\
{[\mu \mathrm{m}]}\end{array}$ \\
\hline \multirow{3}{*}{100} & Laser & 43 & 176 & 398 & 7 & 60 & 23 & 94 \\
\cline { 2 - 9 } & 4 & 19 & 78 & 193 & 4,9 & 34 & 10,3 & 41 \\
\cline { 2 - 9 } & 6 & 17 & 75 & 215 & 3,5 & 23 & 8,4 & 30 \\
\cline { 2 - 10 } & 8 & 21 & 80 & 252 & 4,1 & 30 & 10 & 32 \\
\hline
\end{tabular}

Tabela I zawiera parametry 3D i 2D chropowatości uzyskanej dla różnych parametrach procesu. W wyniku nagniatania uzyskano ponad dwukrotną redukcję wartości amplitudowych parametrów chropowatości i falistości powierzchni w stosunku do próbek tylko stopowanych.

\section{Mikrostruktura warstwy wierzchniej}

Dla pojedynczych ścieżek laserowych przetapianych z prędkością $100 \mathrm{~mm} / \mathrm{min}$ głębokość strefy przetopionej wynosiła od 0,33 do 0,37 mm. Różnice maksymalnej grubości utworzonej warstwy wierzchniej są mniejsze niż dla strefy przetopu, jej wartości wynoszą 1,4-1,6 mm. Dla prędkości obróbki $200 \mathrm{~mm} / \mathrm{min}$ głębokość strefy stopowej wynosi od 0,24 do 0,31 mm, a maksymalna głębokość zmian strukturalnych warstwy wierzchniej 0,96-1,2 mm. Przy obróbce wielościeżkowej głębokość strefy przetopionej ulega zwiększeniu wraz z liczbą przejść wiązki laserowej i dla obróbki z prędkością równą $300 \mathrm{~mm} / \mathrm{min}$ wynosi 0,26-0,48 mm. Cał-
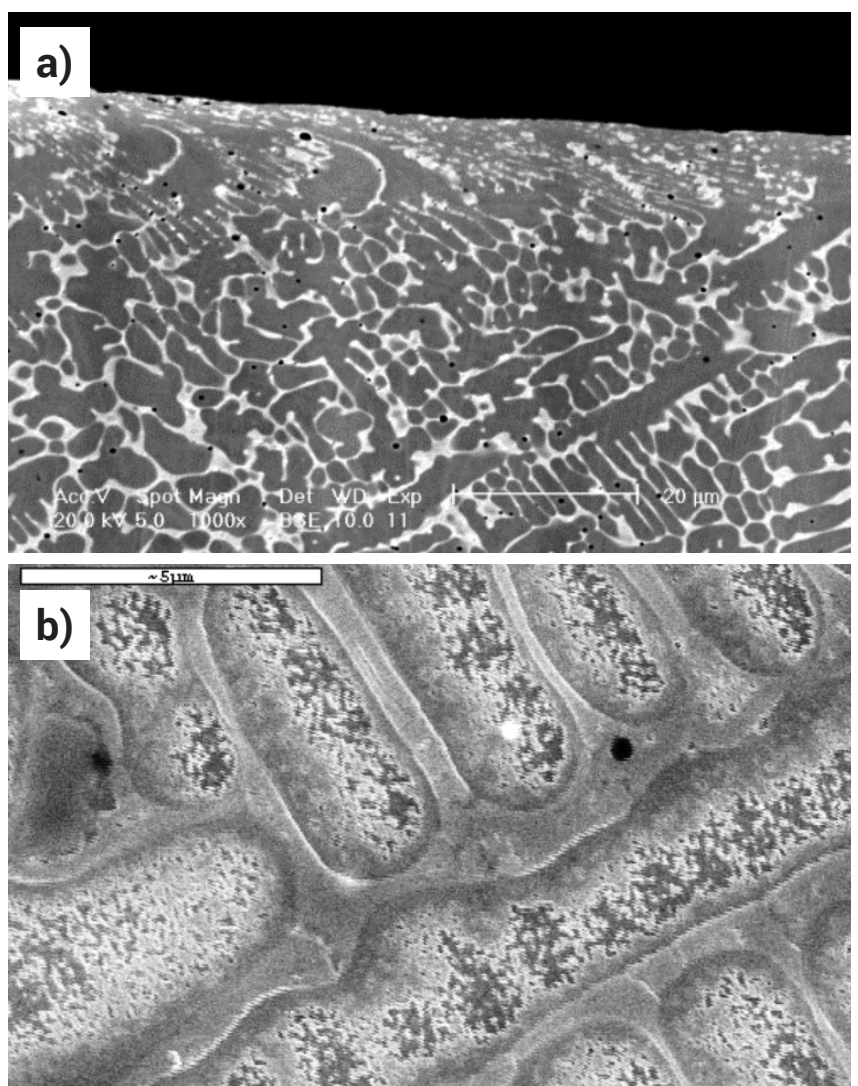

Rys. 3. a) Mikrostruktura WW przy powierzchni materiału: widoczne zgniecione ziarno przy powierzchni-; b) - struktura dendrytyczna - SEM Fig. 3. a) Microstructure of the surface layer near the material surface: deformed grains beneath the surface are visible; b) - dendrite observed on surface of thin foil with SEM method kowita głębokość zmian strukturalnych wynosi ok. 1,4 mm. Największe różnice grubości WW stwierdzono pomiędzy pierwszą i ostatnią ścieżką laserową.

Materiał w strefie przetopienia posiada strukturę dendrytyczną, a pod nią występuje strefa wpływu ciepła o strukturze martenzytycznej i martenzytyczno-ferrytycznej. Nie zaobserwowano pęknięć w warstwie wierzchniej.

$\mathrm{Na}$ rysunku 3a przedstawiono mikrostrukturę strefy stopowanej pojedynczej ścieżki po stopowaniu i nagniataniu ślizgowym w przekroju prostopadłym do osi ścieżki. Widoczne są dendryty, których kierunek osi jest zgodny z kierunkiem odprowadzania ciepła. Można stwierdzić obecność zdeformowanego ziarna w strefie o grubości około 20-30 $\mu \mathrm{m}$, kierunek odkształcenia zgodny jest z kierunkiem oddziaływania narzędzia.

Analiza struktury i składu fazowego wykazała, że po stopowaniu laserowym struktura materiału składa się z ferrytu i austenitu otoczonych szkieletami złożonymi z węglików typu $\mathrm{M}_{6} \mathrm{C}$ i $\mathrm{M}_{23} \mathrm{C}_{6}$. Na rysunku 3b przedstawiono mikrostrukturę obserwowaną na powierzchni cienkich folii metodą STEM w odległości około $50 \mu \mathrm{m}$ od powierzchni. Widoczny jest ciemny szkielet złożony z węglików, który otacza obszary Fea i Fe $\gamma$.

\section{Mikrotwardość warstwy stopowanej}

Na rysunku 4 przedstawiono wyniki pomiarów mikrotwardości w środkowym obszarze przetopienia dla pojedynczej ścieżki laserowej po stopowaniu laserowym stellitem oraz stopowaniu i nagniataniu ślizgowym prowadzonym przy różnych odległościach narzędzia nagniatającego od osi wiązki: $x=4$ i $x=6 \mathrm{~mm}$, a więc różnych temperaturach. Po obróbce hybrydowej osiągnięto ponad $30 \%$ wzrost twardości w stosunku do stopowania laserowego w strefie o grubości około $0,15 \mathrm{~mm}$. Przy odległości między osią wiązki a elementem nagniatającym równej $4 \mathrm{~mm}$ wartość mikrotwardości jest prawie stała na całej głębokości przetopienia.

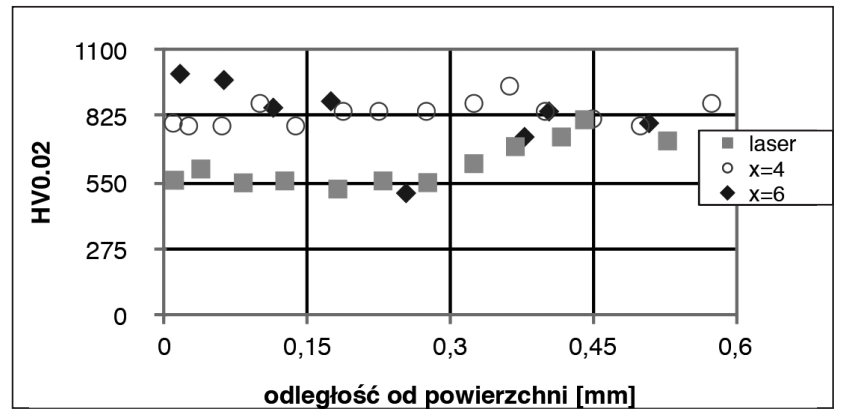

Rys. 4. Mikrotwardość warstwy wierzchniej w pobliżu osi pojedynczej ścieżki skanowania po stopowaniu laserowym i obróbce hybrydowej $(\mathrm{F}=100 \mathrm{~N}, \mathrm{x}=4$ i $6 \mathrm{~mm}, \mathrm{v}=550 \mathrm{obr} / \mathrm{min})$

Fig. 4. Microhardness of the surface layer near the axis of the single scanning path after the laser alloying and for the hybrid machining ( load $100 \mathrm{~N}, \mathrm{x}=4 \mathrm{~mm}$ and $6 \mathrm{~mm}$, rotational speed of head $550 \mathrm{rev} / \mathrm{min}$ ) 
Pomiary mikrotwardości po stopowaniu wielościeżkowym przeprowadzono dla próbki stopowanej laserowo oraz stopowanej i nagniatanej z siłą 65 i 100 N wzdłuż linii równoległej do powierzchni w odległości około $100 \mu \mathrm{m}$. Stwierdzono duże różnice twardości pomiędzy kolejnymi przejściami wiązki laserowej. Twardość materiału jest najniższa w obszarze jednokrotnie przetapianym w pierwszej ścieżce i wynosi około 800 HV. Najwyższa twardość występuje w okolicy ostatniej ścieżki laserowej 1100-1200 HV. Fluktuacje twardości związane są z niejednorodnościami mikrostruktury wywołanymi oddziaływaniem ciepła przy kolejnych przejściach lasera. W obszarach tych występuje przyrost twardości związany z zachodzeniem przemiany martenzytycznej, a także zmianą składu chemicznego warstwy stopowej związanej z większą głębokością przetopienia ostatniej ścieżki (około 0,48 mm) w stosunku do pierwszej $-0,26 \mathrm{~mm}$. Proces nagniatania spowodował wzrost twardości w warstwie przy powierzchni o grubości około $100 \mu \mathrm{m}$. Przyrost twardości przy powierzchni jest większy dla drugiej ścieżki poddanej wielokrotnemu nagrzewaniu i nagniataniu.

a)

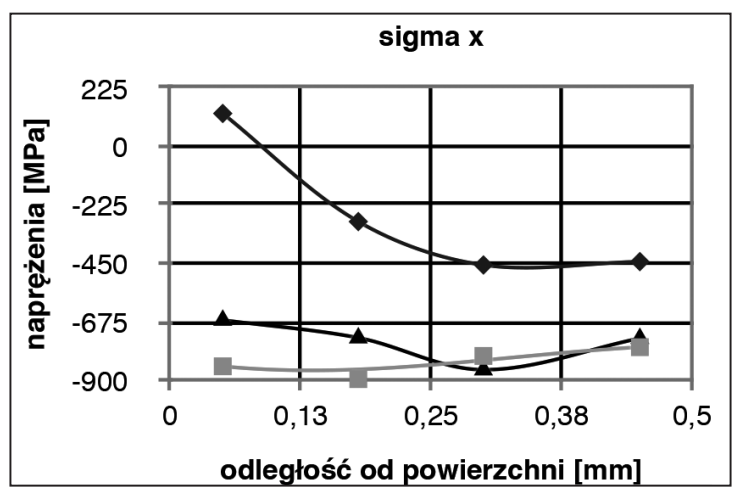

b)

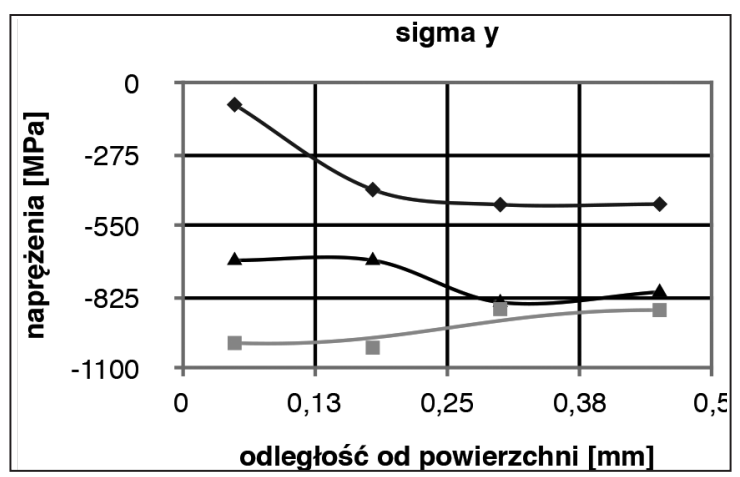

Rys. 5. Wartości naprężenia a) $\sigma_{x}$ b) $\sigma_{y}$ w funkcji odległości od powierzchni w pobliżu osi czwartej ścieżki laserowej próbek po stopowaniu wielościeżkowym $\diamond$ stopowaniu i nagniataniu na zimno i gorąco Fig. 5. Residual stress values a) $\sigma_{x}$, b) $\sigma_{y}$ in function of distance from surface in vicinity of the fifth laser axis of the sample after multiple alloying- $\diamond$ and alloying combined with cold - and hot burnishing

\section{Wyniki pomiarów makronaprężeń własnych}

Badania naprężeń własnych po procesie stopowania oraz stopowania połączonego z nagniataniem ślizgowym przeprowadzono dla próbki po obróbce wielościeżkowej, na której wykonano sześć ścieżek laserowych o stopniu przykrycia około 50\%. Odległość narzędzia nagniatającego od osi wiązki laserowej wynosiła $6 \mathrm{~mm}$, siła nacisku $\mathrm{F}=100 \mathrm{~N}$. Ze względu na wielokrotne przetapianie i nagniatanie na gorąco sąsiadujące ze sobą ścieżki laserowe były wielokrotnie nagniatane również po procesie stopowania w niskich temperaturach. Badania powtórzono dla próbki nagniatanej na zimno w identycznych warunkach. Ze względu na różnice twardości i grubości strefy przetopienia pomiędzy kolejnymi ścieżkami badania przeprowadzono w okolicy czwartej ścieżki laserowej. Pomiary naprężenia przeprowadzono na powierzchni materiału oraz w odległości: $0.05,0.18,0.3,0.45 \mathrm{~mm}$ od powierzchni.

$\mathrm{Na}$ rysunku $5 \mathrm{a}$ i b przedstawiono zmiany wartości naprężenia w funkcji odległości od powierzchni w pobliżu osi czwartej ścieżki laserowej próbek po stopowaniu wielościeżkowym oraz stopowaniu i nagniataniu na zimno i gorąco.

W wyniku procesu nagniatania do warstwy wierzchniej materiału wprowadzone zostały naprężenia ściskające. Naprężenia rozciągające stwierdzono tylko w przypadku próbki stopowanej laserowo. Na powierzchni w pobliżu osi drugiej ścieżki wartość naprężenia wynosiła $\sigma_{x}=+556$ $\pm 60 \mathrm{MPa}$, a dla czwartej ścieżki laserowej $\sigma 0,05 \mathrm{~mm}$ pod powierzchnią $\sigma_{\mathrm{x}}=+126 \pm 18 \mathrm{MPa}$. W większej odległości od powierzchni $w$ obszarze stopowanym stwierdzono naprężeń ściskających rzędu $\sigma_{\mathrm{x}}=-400 \mathrm{MPa}$. Obecność naprężeń ściskających w warstwie przetapianej laserowo związana jest prawdopodobnie z występowaniem naprężeń strukturalnych. W obszarze tym stwierdzono wysoką twardość materiału powyżej 1000 HV 0.02 i można zaobserwować obecność drobnego martenzytu, którego nie obserwuje się przy powierzchni materiału.

W przypadku próbki stopowanej i poddanej procesowi nagniatania na zimno stwierdzono w badanym obszarze duże naprężenia ściskające, ich wartość jest stała w całej strefie przetopienia wynosi około $\sigma_{\mathrm{x}}=-800 \mathrm{MPa}$. Nie stwierdzono istotnych różnic pomiędzy 2-gą i 4-tą ścieżką laserową. Przy dnie przetopu wartość naprężeń jest dwukrotnie większa niż w przypadku próbki tylko stopowanej, co wskazuje, że wpływ zgniotu obejmuje całą strefę stopowa.

Dla próbki stopowanej i nagniatanej w podwyższonej temperaturze $X=6 \mathrm{~mm}$ wartość naprężeń w pobliżu 4- tej ścieżki wynoszą $\sigma_{x}=-660 \pm 60 \mathrm{MPa}$ przy powierzchni i $-860 \mathrm{MPa}$ w odległości około 0,3 mm od powierzchni. Wartości naprężeń różnią się od próbki stopowanej i nagniatanej na zimno w obszarze przy powierzchni, co może być związane z częściową relaksacją naprężeń wywołaną wpływem ciepła przy wykonywaniu kolejnych ścieżek laserowych. Zarówno dla próbki nagniatanej na zimno jak i na gorąco wartości naprężeń $\sigma_{y}$ mają zbliżone, ale nieznacznie większe wartości.

\section{Wnioski}

Przedstawione wyniki badań wskazują, że obróbka hybrydowa pozwoliła na redukcję chropowatości powierzchni oraz wprowadzenie naprężeń ściskających do warstwy wierzchniej materiału stopowanego.

Po procesie nagniatania występuje strefa steksturowana o grubości około 20-30 $\mu \mathrm{m}$. Mirostruktura stali po stopowaniu stellitem kobaltowym składa się z ferrytu, austenitu oraz węglików głównie M6C i M23C6. Stwierdzono, że ilość poszczególnych faz ulega zmianie w zależności od miejsca badania szczególnie w przypadku stopowania wielościeżkowego. Proces nagniatania prowadzi do wzrostu twardości materiału w strefie przy powierzchni. 
Pomiary naprężeń w WW próbek wykazały, że proces nagniatania wprowadził do warstwy wierzchniej materiału stopowanego naprężenia ściskające. W przypadku procesu stopowania wielościeżkowego uzyskano naprężenia rozciągające rzędu $\pm 500 \mathrm{MPa}$. W wyniku nagniatania uzyskano wartość naprężeń przy powierzchni rzędu $-600 \mathrm{MPa}$. Przedstawione wyniki badań stanu warstwy wierzchniej wskazują ze dzięki proponowanej obróbce hybrydowej możliwe jest zwiększenie trwałości elementów po stopowaniu laserowym.

\section{Literatura}

[1] J.R. Robinson A. B. Van Brussel, J. Th.M. De Hosson, R.C. Reed, $\mathrm{X}$ ray measurement of residual stresses in laser melted Ti-6Al- $\mathrm{V}$ alloy, Material Science and Engineering A208, s. 143-147, 1996.

[2] B.G. Gireń, M. Szkodo, J Steller, The influece of rsidual stresses on cavitation resistance of metals- an analysis based on invesigations of metals remelted by laser beam and optical discharge plasma, Wear233-235, s.86-92, 1999.

[3] H. Gripenberg, et al. Prediction and Measurement of Residual Stresses in Cladded Steel, Materials Science Forum, vol. 404-407, s. $861-866,2010$.

[4] J. Grum, M. Znidarsic, Strain Measurement during Laser Surface Cladding of Low Carbon Steel and Analisis of Residual Stresses, Materials Science Forum, vol. 404-407, s. 437-444.

[5] Cheng W., Finnie I., Gremaud M., Rosselet A., Streit R.D.: The Compliance Method for Measurement of Near Surface Residual Stresses - Application and Validation for Surface Treatment by Laser and ShotPeening. Transactions of the ASME, vol. 116, s. 1242-253, 1994.

[6] M. Ignatiev, E Kovalev, I. Melekhin, I. Sumurov, S. Surlese, Investigation of the hardening of titanium alloy by laser nitriding. Wear, vol.166, s. $233-236,1993$.

[7] J. Th. M. De Hosson, J Noordhuis, Surface Modification by Means of Laser Melting Combined with Shot Peening: a Novel Approach. Material Science and Engineering, vol. A121, 1989.

[8] J.P Kruth., H.K Tonshoff., F. Klocke, Surface and Sud-Surface Quality in Material Removal Processes for Tool Making. 12th International Symposium for Electomachining (ISEM), Aachen, Germany, 11-13 May 1998.

[9] M. Jankowiak Laserowe wspomaganie toczenia twardej ceramiki Si3N4. Wybrane Zagadnienia Obróbek Skoncentrowaną Wiązką Energii (Konferencja EM 2003), Bydgoszcz, s. 184-192, 2003.

[10] J. Radziejewska, Laserowa modyfikacja właściwości warstwy wierzchniej wspomagana nagniataniem. Prace IPPT - PAN, Warszawa 3/2011, ISBN 978-83-89687-70-8.

[11] J. Radziejewska, S. Skrzypek, Microstructure and residual stresses in surface layer of simultaneously laser alloyed and burnished steel. $\mathrm{J}$ of Materials Processing Technology, vol. 209, s. 2047-2056, 2009. 